\title{
Editorial: Citizen Science for Future Generations
}

\author{
Reuven Yosef ${ }^{1 *}$ and Piotr Tryjanowski ${ }^{2,3}$ \\ ${ }^{1}$ Ben Gurion University of the Negev, Eilat, Israel, ${ }^{2}$ Department of Zoology, Poznan University of Life Sciences, Poznan, \\ Poland, ${ }^{3}$ Faculty of Environmental Sciences, Czech University of Life Sciences Prague, Prague, Czechia
}

Keywords: animals, future, mass-media, schooling, teaching

\section{Editorial on the Research Topic}

\section{Citizen Science for Future Generations}

Schooling is a concept that is as ancient as human history. Initially, offspring learnt to survive and subsist from their parents and immediate families/tribe. Later in history, with the evolvement of agricultural societies, they learnt trades. Eventually, with the industrial revolution in the mid-19th century that required concentrated man-power and children's rights evolved (cf. Dickens, 1838), the concept of central schooling was invented. However, while the education within family groups remains similar between generations, the schooling system attempted to evolve into a modernized version that attempted to keep up with technological development and increasing, cumulative knowledge of the human society. The concept behind it being that the children should be able to meet the needs and expectations of the future when they become adults (Targamadze, 2019). This attempt to keep up with modernization over the past three centuries has resulted in varying results, especially in countries with poor economies or depressed by other communities (e.g., colonialism, economic exploitation; Woolford, 2013). In recent decades, environmental awareness has led to changes in the curriculum taught in schools and is evolving with different methodologies. One of the most recent of these methods that has developed is Citizen Science (cf. Strasser et al., 2019).

Strasser et al. (2019) made the distinction between "amateur naturalists" of the past two centuries where people of different professions, for whom their scientific occupation was a "hobby," was mostly unpaid, and hence before the mid-19th century was mostly conducted by "citizen science" (see also Haklay, 2013). Since the introduction of modern Citizen Science techniques, there are several descriptions which show how it has also diversified almost instantaneously ranging from "science that serves the citizens" (Irwin, 1995) to "science performed by the citizens", i.e., science performed for the people, by the people (Strasser et al., 2019). However, today it is mainly conceptualized as allowing citizens to contribute to ongoing scientific research, whether with (eBird, 2002) or without their knowledge by taking advantage of a range of public-media platforms (Mikula, 2015; Dylewski et al., 2017). Bonney et al. (2016) presented a typology of how Citizen Science projects could be characterized: (1) contributory projects wherein scientists design the experiment and citizens contribute data (e.g., North America Christmas Bird Count); (2) collaborative projects wherein the public can also voice opinions and contribute to project design, help analyze the data, and even disseminate the findings; or (3) co-created projects wherein public participants are involved in the whole process of developing and implementing the scientific process.

A wide range of projects have developed over time wherein innovative scientists have successfully incorporated citizens into their data-collection process. An example of a globally active project is eBird by the Cornell Lab of Ornithology wherein the public share their field observations, and which allows scientists to mine for their relevant projects (e.g., Callaghan et al., 2020, 2021). There are many such projects in almost every field of interdisciplinary sciences and 
ranges from astronomy (Galaxy Zoo) through medicine (PatientsLikeMe), to the environment (Penguin Watch). Also, an increasing number of professional networks for Citizen Science have been founded (US-based Citizen Science Association, European Citizen Science Association, Australian Citizen Science Association, Israel's Taking Citizen Science to Schools).

In order to pull these efforts together, and to try and understand how and what efforts are made, to better equip the next generations to be good Citizen Scientists. A total of 11 papers have been included in this special issue about "Perspectives in education and Citizen Science in the next generations." We hope that the projects included will serve as examples of how the upcoming generation can be primed as potential help for gathering large quantities of data with minimal investment of time and effort.

Citizen Science has been applied to a wide range of issues including beaches (Fanini et al.), biodiversity monitoring in the Red Sea (Meschini et al.), marine invasive species (Encarmacao et al.), True Hoppers (Kitteleberger et al.), avian ecology (Lefebvre, 2020) and recreational birdwatching (Randler), and the surveillance of Coastal Redwoods (Sequoia sempervirens) (Young et al).

Another example of how attitudes toward wildlife can be evaluated and influenced is that of Prokop et al. who wished to understand how they could make conservation more effective by improving human attitudes. The authors investigated whether animal posture influences human willingness to protect animals by manipulating animal postures and examined perceived cuteness, fear, and the willingness to protect them. Responses from 349 adults showed that bipedal posture increased cuteness, lowered fear, and increased willingness to protect, but this effect works specifically in the case of small species (e.g., a ground squirrel); and the opposite in larger species (e.g., a bear). Interestingly, the strongest positive effect of bipedalism was when the animal was not only small, but also phylogenetically closer to humans (i.e., a mammal is closer than an insect) and with direct eye contact. They concluded that bipedal posture in large-bodied species is perceived as threatening, because these animals look even bigger than they are and could be perceived dangerous.

All said many of the projects included in this special issue involve adults. It is only in recent years that scientists are exploring the possibilities of school children conducting scientific projects (Schleicher and Schmidt, 2020). This came at a very opportune moment because many of the schools had reached a point of knowledge-satiation (eutrophication; Targamadze, 2019) and was casting about for ways in which to involve students in projects and to arouse their interest in the mundane process of school learning. The education systems started incorporating environmental studies under the umbrella of the sciences. Hence, the introduction of Citizen Science projects came at a very opportune time and was readily accepted by the system (Sheard et al., 2020). Sandén et al., demonstrate how the Tea Bag Index App facilitated the inclusion of a subject neglected by schools-soil science and its connection to climate change. Together with the schools, they collected important data pertaining to the carbon cycle, gave inspiration to the teachers, and awakened interest among the participating school students; and allowed them to collect data across Austria. In this manner the study makes a big contribution to the understanding of global patterns in the carbon cycle. Similarly, Spellman et al. emphasized to children the process of climate change and decision making through the evaluation of their ability to sustain berry resources for their communities.

However, not all experiments were successful, and the reactions of the scientists range from the skeptical (Castagneyrol et al., 2020; Rouviere and Ruxton, 2021), to those preaching to be careful (Schulwitz et al., 2018), and to those who feel that they are not fully realized (Cohn, 2008; Battisti et al., 2020; Callaghan et al., 2020). Castagneyrol et al. (2020), in the framework of an on-going project Oak Bodyguards applied existing standardized protocols to estimate predation rates on artificial caterpillars placed on low branches of oak trees, and insect herbivory on randomly collected fresh oak leaves. They found that although most of the schools estimated attack rates, none analyzed the herbivory part of the experiment. They concluded that the results obtained by schoolchildren were like that of untrained professionals, and that the raw data acquired by schoolchildren require several quality checks by professional scientists before they can be used. Although in general we agree with that said, we feel these results should be considered in a more nuanced manner as similarly to untrained professionals and were not equipped with the proper tools before being asked to collect the data. Also, the fineness/resolution of the data being collected should be taken into consideration. In their case, Castagneyrol et al. (2020) built upon an ongoing Citizen Science program and assessed the ability of schoolchildren to accurately estimate the strength of biotic interactions in terrestrial ecosystems. However, in this study no information was provided on the ages of the children involved in the study. We think this is very important because children mature with years and acquire greater manipulative and behavioral traits which are lacking in younger children (Yosef et al., 2021a). Hence, the age at which Citizen Science projects can be properly accomplished by school children is a factor of how well they have developed their behavioral, cognitive, and motoric capabilities (Norton et al., 2005), including their concentration and observational capabilities (McClelland et al., 2013). We also contend that the subject of how well they are trained prior to data collection influences subsequent data quality perceptions of complex ecosystems (Sheard et al., 2020; Gal et al., 2021).

However, it is of importance that the "baby not be thrown out with the water." Hence, although there are drawbacks to involving citizen science, especially with school children, Arazy and Malkinson emphasized the need for citizen science programs to collect data that allow for robust statistical analyses in order to effectively support evidence-based wildlife conservation and management. They think that integrating Citizen Science data with other, more traditionally collected datasets can improve population estimates and inferences. They illustrated their questionnaire's ability to capture the factors driving observerbased biases by employing data from a local project on the iNaturalist platform. Also using the iNaturalist mobile app, Young et al. provide the first explicit example of a Citizen Science project using a Translational Science Education (TSE) framework, which brings educators and researchers together 
to produce both actionable science and authentic learning experiences. By investigating urbanization in a coastal redwoods (Sequoia sempervirens) region of California, in collaboration with local students and educators, they show how a TSE-based citizen science project can result in both learning and data generation. Qualitative reports by educators showcase the power of TSE approaches to engage students and teach environmental stewardship practices. Their case study provides insights that can inform the development and structure of future TSE efforts, while highlighting the ability of the TSE framework to connect and benefit students and researchers during citizen science projects. Further, Sun et al. with a citizen science program called iSeeMammals developed in New York state in 2017 to supplement costly systematic spatial capture-recapture sampling by collecting opportunistic data from one-off observations, hikers, and camera traps. The triumvirate of increased spatial and temporal coverage by at least 2 -fold compared to systematic sampling, an $83 \%$ reduction in annual sampling costs, and improved density estimates of the American black bear (Ursus americanus) when integrated with systematic data highlight the benefits of collecting presence-absence data in citizen science programs for estimating population patterns.

In our efforts to equip the next generation with the proper tools for scientific thought and decision-making, we are involved for the past decade in teaching scientific research at a high school in southern Israel (e.g., Yosef et al., 2020). In the framework of the Israeli Ministry of Education we recruit school children between the ages of 15 and 17 years old to engage in a yearlong scientific project wherein they are taught scientific thought, techniques and then do several months of field work (minimum $60 \mathrm{~h}$ of field observations) and write up a thesis and given course credit for the final certificate (cf. Yosef et al., 2021a). The scientific projects are also recognized by academic institutions of higher education and these students are given bonus points when they register and are an incentive for many of the students. Over the past 10 years we have worked with 183 students who chose to be involved in research over and above all their regular school requirements. We did not include the data for 2020-2021 because of the COVID-19 lockdowns which resulted in many abandoning their projects owing to lack of access to their project sites or laboratories. We divided their individual projects into coarse and fine projects. We considered coarse projects $(N=113)$ to be those wherein the children had to observe wild animals and their responses to various cues in the environment. The rest $(N=70)$ chose projects that were confined to laboratories/zoos/aquariums and were based on manipulations of experiment-specific parameters. All the students were tutored for 3-months prior to beginning their projects and we evaluated their progress. We discovered that children that worked in closed areas appeared to lose interest at some stage, were not punctual, and the drop-out was relatively high and only $68 \%(N=78)$ submitted their thesis (Yosef et al., 2021a,b). In contrast, children that choose to work in the field were highly motivated and enthusiastic, adhered to the scientific protocol specified beforehand, were punctual at their observation posts, and took their project seriously resulting in $93 \%(N=$ 105) of them successfully submitting their thesis. Of the latter, owing to the high quality of their data, were also involved in scientific publications (e.g., Yosef et al., 2020, 2021b). We find that children who were well-prepared and rehearsed with the research techniques also performed well in the field during data collection. These results are like that found in the teabag experiments that were conducted worldwide (Keuskamp et al., 2013; Sandén et al.).

It is of interest to note that children, apparently more so than adults, are susceptible to fears and erroneous falsifications (Broomfield et al., 2002), especially when it comes to animals (Porot and Mandelbaum, 2021). Hence, it is of interest that Zvaríková et al. tried to elucidate what is so frightening and disgusting in spiders and that can result in arachnophobia in humans. They manipulated a real picture of a spider and enlarged its eyes, body hair, opistosoma (abdomen), chelicerae and legs and the series of photographs were rated by many people in Slovakia. They concluded that fear and disgust was triggered by enlarged chelicerae, abdomen, and the presence of body hair. In contrast, longer legs were associated with fear, but enlarged eyes were not. They conclude that people are afraid of enlarged animal weapons that are threatening. The enlarged abdomen resembled a big tick or a blood-sucking invertebrate and was considered disgusting. The study illustrated that to raise empathy amongst the laymen one should not use spiders with big abdomens and dense body hair as a flagship species.

In conclusion, we find that Citizen Science, whether pertaining to that collected randomly or systematically by adults, or in a structured, pre-planned manner by school children, can contribute to science but requires advance preparation and investment of time, energy, and resources. Yet, in spite of the drawbacks of the young age and inexperience of the high school children, we consider it pertinent to continue to educate them to become responsible citizens in their communities, to know how to plan and execute projects, and how to make resultbased decisions especially as policymakers. We believe that if we equip the future generations with the correct tools at a younger age, we ensure the recruitment of responsible citizens into our communities in the future.

\section{AUTHOR CONTRIBUTIONS}

RY and PT: conceptualization, organization, correspondence, reviews, and final draft. RY: first draft. All authors contributed to the article and approved the submitted version. 


\section{REFERENCES}

Battisti, C., Gustin, M., and Polinori, A. (2020). Do the weaknesses and strengths of experts and local volunteers affect the conservation actions focused on nesting plovers? Constructive considerations from the Italian beach front line. Avocetta 44, 105-111. doi: 10.30456/AVO.2020205

Bonney, R., Phillips, T. B., Ballard, H. L., and Enck, J. W. (2016). Can citizen science enhance public understanding of science? Public Understand. Sci. 25, 2-16. doi: 10.1177/0963662515607406

Broomfield, K. A., Robinson, E. J., and Robinson, W. P. (2002). Children's understanding about white lies. Br. J. Dev. Psychol. 20, 47-65. doi: 10.1348/026151002166316

Callaghan, C. T., Sayol, F., Benedetti, Y., Morelli, F., and Sol, D. (2021). Validation of a globally-applicable method to measure urban tolerance of birds using citizen science data. Ecol. Indic. 120,106905. doi: 10.1016/j.ecolind.2020.106905

Callaghan, C. T., Wilshire, J. H., Martin, J. M., Major, R. E., Lyons, M. B., and Kingsford, R. T. (2020). The Greenspace Bird Calculator: a citizen-driven tool for monitoring avian biodiversity in urban greenspaces. Austr. Zool. 40, 468-476. doi: 10.7882/AZ.2019.009

Castagneyrol, B., Valdés-Correcher, E., Bourdin, A., Barbaro, L., Bouriaud, O., Branco, M., et al. (2020). Can school children support ecological research? Lessons from the Oak Bodyguard Citizen Science Project. Citizen Sci. 5, 1-11. doi: $10.5334 /$ cstp. 267

Cohn, J. P. (2008). Citizen science: Can volunteers do real research? Bioscience 58, 192-197. doi: 10.1641/B580303

Dickens, C. (1838). Oliver Twist. London: Bentley's Miscellany. doi: 10.1093/oseo/instance.00121337

Dylewski, Ł., Mikula, P., Tryjanowski, P., Morelli, F., and Yosef, R. (2017). Social media and scientific research are complementary - YouTube and shrikes as a case study. Sci. Nat. 104,48. doi: 10.1007/s00114-017-1470-8

eBird (2002). About. Available online at: https://ebird.org/about (accessed December 17, 2021).

Gal, A., Gan, D., and Ben Zvi-Assaraf, O. (2021). The use of the lesser kestrel's life cycle to enhance elementary school children's' under-standing of complex systems. Interdiscipl. J. Environ. Sci. Educ. 17,e2226. doi: 10.29333/ijese/ 9152

Haklay, M. (2013). "Citizen science and volunteered geographic information: overview and typology of participation," in Crowdsourcing Geographic Knowledge, eds D. Sui, S. Elwood, and M. Goodchild (Dordrecht: Springer). doi: 10.1007/978-94-007-4587-2_7

Irwin, A. (1995). Citizen Science: A Study of People, Expertise, and Sustainable Development. London; New York, NY: Routledge.

Keuskamp, J. A., Dingemans, B. J., Lehtinen, T., Sarneel, J. M., and Hefting, M. M. (2013). Tea Bag Index: a novel approach to collect uniform decomposition data across ecosystems. Methods Ecol. Evol. 4, 1070-1075. doi: 10.1111/2041-210X.12097

Lefebvre, L. (2020). A global database of feeding innovations in birds. Wilson J. Ornithol. 132, 803-809. doi: 10.1676/20-00101

McClelland, M. M., Acock, A. C., Piccinin, A., Rhea, S. A., and Stallings, M. C. (2013). Relations between preschool attention span-persistence and age 25 educational outcomes. Early Child. Res. Q. 28, 314-324. doi: 10.1016/j.ecresq.2012.07.008

Mikula, P. (2015). Fish and amphibians as bat predators. Euro. J. Ecol. 1, 71-80. doi: $10.1515 /$ eje-2015-0010
Norton, A., Winner, E., Cronin, K., Overy, K., Lee, D. J., and Schlaug, G. (2005). Are there pre-existing neural, cognitive, or motoric markers for musical ability? Brain Cogn. 59, 124-134. doi: 10.1016/j.bandc.2005.05.009

Porot, N., and Mandelbaum, E. (2021). The science of belief: A progress report. Wiley Interdiscipl. Rev. 12:e1539. doi: 10.1002/wcs.1539

Rouviere, A., and Ruxton, G. D. (2021). No evidence for magnetic alignment in domestic dogs in urban parks. J. Vet. Behav. 2021:5. doi: $10.1016 /$ j.jveb.2021.11.005

Schleicher, K., and Schmidt, C. (2020). Citizen science in Germany as research and sustainability education: Analysis of the main forms and foci and its relation to the sustainable development goals. Sustainability 12,6044. doi: $10.3390 /$ su12156044

Schulwitz, S. E., Spurling, D. P., Davis, T. S., and McClure, C. J. (2018). Webcams as an untapped opportunity to conduct citizen science: six years of the American Kestrel Partnership’s KestrelCam. Glob. Ecol. Conserv. 15:e00434.

Sheard, J. K., Sanders, N. J., Gundlach, C., Schär, S., and Larsen, R. S. (2020). Monitoring the influx of new species through citizen science: The first introduced ant in Denmark. PeerJ 8,e8850. doi: 10.7717/peerj.8850

Strasser, B. J., Baudry, J., Mahr, D., Sanchez, G., and Tancigne, E. (2019). Citizen Science? Rethinking Science and Public Participation. Available online at: https:// archive-ouverte.unige.ch/unige:100156 (accessed December 17, 2021).

Targamadze, V. (2019). General education school: process of eutrophication. Soc. Educ. 52, 6-16. doi: 10.15823/su.2019.52.1

Woolford, A. (2013). Nodal repair and networks of destruction: residential schools, colonial genocide, and redress in Canada. Settler Colonial Stud. 3, 65-81. doi: 10.1080/18380743.2013.761936

Yosef, R., Hershko, M., and Zduniak, P. (2021b). Anti Covid-19 face-masks increases vigilance in Nubian ibex (Capra nubiana). Biol. Conserv. 263,109339. doi: 10.1016/j.biocon.2021.109339

Yosef, R., Raz, M., Ben-Baruch, N., Shmueli, L., Kosicki, J. Z., Fratczak, M., et al. (2020). Directional preferences of dogs' changes in the presence of a bar magnet: Educational experiments in Israel. J. Vet. Behav. 35, 34-37. doi: $10.1016 /$ j.jveb.2019.10.003

Yosef, R., Talker, S., and Sadeh, I. (2021a). Effect of COVID-19 closures and distance-learning on biology research projects of high school students in Israel. Educ. Sci. 11,716. doi: 10.3390/educsci11110716

Conflict of Interest: The authors declare that the research was conducted in the absence of any commercial or financial relationships that could be construed as a potential conflict of interest.

Publisher's Note: All claims expressed in this article are solely those of the authors and do not necessarily represent those of their affiliated organizations, or those of the publisher, the editors and the reviewers. Any product that may be evaluated in this article, or claim that may be made by its manufacturer, is not guaranteed or endorsed by the publisher.

Copyright (ङ 2022 Yosef and Tryjanowski. This is an open-access article distributed under the terms of the Creative Commons Attribution License (CC BY). The use, distribution or reproduction in other forums is permitted, provided the original author(s) and the copyright owner(s) are credited and that the original publication in this journal is cited, in accordance with accepted academic practice. No use, distribution or reproduction is permitted which does not comply with these terms. 